\title{
Research on the County Water Resources Carrying Capacity in the New Period
}

\author{
Jinxing $\mathrm{Li}^{1,{ }^{1,}, \text { Lianfeng } \mathrm{Ke}^{2} \text {, Le Yang }}{ }^{1}$, and Heshuai $\mathrm{Qi}^{1}$ \\ ${ }^{1}$ Zhejiang Institute of Hydraulics and Estuary (Zhejiang Institute of Marine Planning and Design), 310020 Hangzhou, China \\ 2 Wenling City Agriculture, Rural Areas and Water Conservancy Bureau, 317599 Wenling, China
}

\begin{abstract}
With the rapid economic and social development, human disturbances to the ecosystem have become more and more intense. However, the scale of regional economic and social development, supported by regional water resources, has boundaries. The central government and local governments of all levels have clearly proposed to carry out water resources carrying capacity evaluation and early warning. From the perspective of the actual management of the county water administrative department, with the administrative divisions within the county as the basic unit, the principle of index selection and index grading standards determination is proposed, and an index system including the four major levels of society, economy, water resources, and ecology is constructed. Then, combined with the functions of various government departments, the basic framework of a universal water resources carrying capacity early warning mechanism, including three major processes: carrying capacity evaluation and update, early warning information release, and implementation of differentiated control measures, is proposed.
\end{abstract}

\section{Introduction}

For human survival and development, water resources, one of the most important material resources, are indispensable, and is the basic support for economic development and related to economic security, ecological security and national security. Since the economic reform and open up, due to rapid population agglomeration, further acceleration of urbanization, rapid economic and social development, regional water demand and water resources development and utilization have increased significantly, and human disturbances to the ecosystem have become more and more intense. However, the renewable capacity and renewal rate of regional water resources are limited, and the endowment of water resources is quite different. Therefore, the scale of regional economic and social development that regional water resources can support is bounded, and the concept of water resources carrying capacity is thus put forward ${ }^{[1]}$.

The carrying capacity of water resources is to introduce the concept of carrying capacity into the field of water resources, and carry out carrying capacity research with water as a resource. Under this concept, the water resources system is the main body of the carrier, human beings and the economic and social systems and ecosystems on which they depend are the carrier objects, and maintaining the virtuous cycle of the ecosystem is its control objective of the research on the carrying capacity of water resources. The carrying capacity of water resources involves many factors such as economy, social, water resources, ecology, and requires comprehensive research in a composite system ${ }^{[2]}$. General Secretary Xi Jinping pointed out that water has become a severely short product in China, and proposed that the county should be used as a unit to evaluate the carrying capacity of resources and the environment and establish an early warning mechanism. In January 2020, the General Office of the Ministry of Natural Resources clearly proposed to carry out the evaluation of water resources carrying capacity and incorporate it into the resource and environment carrying capacity system. Subsequently, the central government and local governments of all levels clearly stated in the water-saving action plan that water resources carrying capacity evaluation, monitoring and early warning should be carried out.

At present, the research on the carrying capacity of water resources in foreign countries mostly appears in the theory of sustainable development, and the main research directions are the sustainable use of water, indicators of water scarcity, the limit of water resources development based on the health of the natural environment, and the utilization limits of river development and etc ${ }^{[3,4]}$. Through the application of relevant theories and methods to evaluate the degree of regional water resources carrying capacity, the sustainable utilization of regional water resources is analysed. Based on the evaluation results, the government formulates corresponding policies and measures in urban water supply, water resources utilization, and industrial development. Domestic research on water resources carrying capacity started relatively late, but certain research results have been made in recent years. Especially in the concept, connotation, theoretical system, calculation method, evaluation index system, evaluation

\footnotetext{
*Li Jinxing: ljx002@hotmail.com
} 
model of water resources carrying capacity, domestic scholars have done systematic research. Zuo QT ${ }^{[2]}$ divided the domestic water resources carrying capacity research methods into three categories: empirical formula method, comprehensive evaluation method and system analysis method, and proposed that the focus of future water resources carrying capacity research should be basic models, internal mechanisms, water control results, calculations model, system platform, dynamic evaluation, early warning and control, and etc. Xiu HL et al. ${ }^{[5]}$ summarized the experience of water resources carrying capacity control measures in typical regions, and combed the main measures for the two-way control of domestic water resources carrying capacity from the two directions of strong loading and unloading. On the basis of constructing a regional characteristic index system for a specific research area, Yu P et al. ${ }^{[6]}$, Jiang Y et al. ${ }^{[7]}$, Fan $\mathrm{CY}$ et al. ${ }^{[8]}$, Fan $\mathrm{YH}$ et al. ${ }^{[9]}$ respectively adopted aquatic ecological footprint method, principal component analysis method, artificial neural network method and coupling between methods to evaluate the regional water resources carrying capacity.

Overall, the current domestic research is mostly limited to the definition of the concept of water resources carrying capacity, the diversification of evaluation methods, and the analysis of the current regional water resources carrying capacity. Researchers pay more attention to quantitative research on results, and the applicability of the index system is relatively limited. At the same time, there are still few studies on the periodic dynamic update of water resources carrying capacity and the establishment of early warning management and control mechanisms. In the new era, China's economy has shifted from a stage of high-speed growth to a stage of high-quality development. Therefore, how to implement the rigid constraints of water resources through the establishment of water resources carrying capacity monitoring and early warning mechanisms at the county level is an urgent problem to be solved. From the perspective of the management practice of the county water administrative department, this research focuses on the actual water resources management of the county, and proposes to construct the evaluation index system and evaluation method of the regional water resources carrying capacity with the administrative divisions within the county as the basic unit. Then, the regional water resources carrying capacity evaluation model is combined with the digital results of county water resources management and the functions of various government departments to further design the water resources carrying capacity early warning mechanism process framework, and the corresponding management and control measures are studied and proposed in this study.

\section{Construction of evaluation system for water resources carrying capacity}

\subsection{Construction of water resources carrying capacity index system}

\subsubsection{Principles of the index system}

Representativeness. The indicators should have a certain hierarchies of typical representativeness. There are many factors involved in the carrying capacity of water resources. The indicators with strong comprehensiveness and characteristics should be selected to reflect the status of the hierarchies represented as much as possible.

Conciseness. The calculation and measurement of indicators must be simple and clear, and relevant data must be easy to collect. Meanwhile, in order to facilitate the periodic dynamic update of the bearing capacity strength evaluation, the calculation method must be simple and fast.

Regionality. The carrying capacity of different regions is quite different in space. The index system for the carrying capacity of the county should include indicators with regional characteristics.

\subsubsection{Index system}

The evaluation of water resources carrying capacity, influenced and restricted by economy, society, ecological environment, etc., is a relatively complex system. The construction of an index system is the basis for carrying capacity evaluation. Based on the regional resources conditions, the load intensity of the current economic and social development on water resources is the actual focus of the county. Therefore, a total of eight indicators from four aspects dominated by relative indicators are determined to constitute an indicator system, as shown in the following table.

Table 1. Water resources carrying capacity index system

\begin{tabular}{|c|c|c|c|c|}
\hline Target layer & Criterion layer & Index layer & Calculation formula & Indicator type \\
\hline \multirow{5}{*}{$\begin{array}{l}\text { Water } \\
\text { resources } \\
\text { carrying } \\
\text { capacity }\end{array}$} & \multirow[b]{2}{*}{ Water resources } & Water resources per capita $\left(\mathrm{m}^{3} / \mathrm{P}\right)$ & $\begin{array}{l}\text { Water resources/resident } \\
\text { population }\end{array}$ & + \\
\hline & & $\begin{array}{l}\text { Utilization rate of domestic and } \\
\text { industrial water consumption } \\
\text { indicators }(\%)\end{array}$ & $\begin{array}{l}\text { Domestic and industrial water } \\
\text { consumption/domestic and } \\
\text { industrial water consumption } \\
\text { control red line }\end{array}$ & - \\
\hline & \multirow[b]{2}{*}{ Society } & The population density $\left(\mathrm{P} / \mathrm{km}^{2}\right)$ & Population/area & - \\
\hline & & Urbanization rate $(\%)$ & $\begin{array}{c}\text { Urban population/total permanent } \\
\text { population }\end{array}$ & - \\
\hline & Economic & $\begin{array}{c}\text { Water consumption for non- } \\
\text { agricultural GDP per ten } \\
\text { thousand RMB }\left(\mathrm{m}^{3} / \text { ten thousand }\right. \\
\text { RMB) }\end{array}$ & $\begin{array}{c}\text { Non-agricultural water } \\
\text { consumption/non-agricultural GDP } \\
\text { per ten thousand RMB }\end{array}$ & - \\
\hline
\end{tabular}




\begin{tabular}{|l|c|c|c|c|}
\cline { 3 - 5 } & $\begin{array}{c}\text { Water consumption per ten } \\
\text { thousand RMB of industrial } \\
\text { added value }\left(\mathrm{m}^{3} / \text { ten thousand }\right. \\
\mathrm{RMB})\end{array}$ & $\begin{array}{c}\text { Water consumption/ per ten } \\
\text { thousand RMB industrial added } \\
\text { value }\end{array}$ & - \\
\cline { 2 - 5 } & $\begin{array}{c}\text { Water quality compliance rate of } \\
\text { water function zone }(\%)\end{array}$ & Qualified quantity/total quantity & + \\
\cline { 3 - 5 } & Ecology & $\begin{array}{c}\text { Area covered by vegetation/total } \\
\text { area of the area }\end{array}$ & + \\
\hline
\end{tabular}

Note: + represents positive correlation; - represents negative correlation.

\subsubsection{Principles for determining the grading standard of evaluation factors}

The classification of grades is the basis for determining the strength of water resources carrying capacity, but there are still few unified standards for its evaluation. This research considers general issues and proposes the following principles for determining the classification standards.

Orderliness. For existing standards, the grading standards should follow the priority order of international, national, provincial, and municipal levels and adopt the corresponding standards in turn.

Dynamic. With the development of social economy and technological progress, the grading standards should be changed accordingly, and the grading standards should be updated regularly.

Scientificality. For indicators without recognized standards, scientific methods such as expert experience method, total score frequency method or equal interval method should be sought for quantification.

Characteristic. There are existing research results that can be referred to for some indicators. On the basis of considering the actual use of water resources in the county, the grading standards of these indicators should be determined based on the spatial differences between regions.

\subsection{Selection of evaluation methods for water resources carrying capacity}

\subsubsection{Overview of BP neural network model}

Error Back-Propagation (Error Back-Propagation) is abbreviated as BP algorithm, which aims to minimize the error of the output result and is currently the most widely used neural network model ${ }^{[10]}$. It is a one-way multi-layer forward network. The model structure includes an input layer, an output layer, and a hidden layer. The nodes of two adjacent layers are connected by weights, and the threshold that controls the critical value of the node's response. In the specific construction process, in order to solve the problem that the direct analysis and calculation of data of different natures cannot correctly reflect the comprehensive results of different forces and the comparability of data, and to eliminate the influence of different dimensions and magnitude differences of various indicators, data standardization is required. As the input data, the expected result of the index is used as the output layer, and the input layer data is forwarded to the hidden layer. After the activation function of this layer is processed, it is transmitted to the output layer. The error between the results is propagated back to correct the weight of each layer, and the complex internal correspondence between input and output is summarized through continuous learning, and the final BP neural network model is constructed. The topological structure of BP neural network is shown in the figure.

\subsubsection{Overview of Particle Swarm Optimization (PSO) algorithm}

The basic idea of PSO is derived from the study of the foraging behaviour of birds, that is, a group of birds is searching for food at random, and there is only one piece of food in this area. All the birds do not know where the food is, but they know the current location is far away. The distance of food, the simplest and most effective strategy to find food is to search the area around the bird that is currently closest to the food. In the PSO algorithm, the potential solution of each optimization problem can be imagined as a point on the d-dimensional search space, which is a "particle". All particles have an fitness value determined by the objective function, and each particle has A speed determines the direction and distance they fly, and then the particles follow the current optimal particle to search in the solution space, and can perform complex global behaviours through simple and regular interactions. The PSO algorithm is easy to implement, has high solving efficiency, and has strong nonlinear optimization performance. It is a popular algorithm for research and application in the field of optimization.

\subsubsection{PSO-BP neural network model construction}

BP neural network has good performance in self-learning and non-linear mapping, but its convergence speed is slow, and it is very sensitive to initial weights and thresholds, while the BP algorithm connects the initial weights between BP neural network nodes. And the random number with the threshold value in the interval $(0,1)$ has great uncertainty, and the model can easily fall into a local optimal situation, which leads to situations such as unstable prediction results and high and sometimes low prediction accuracy ${ }^{[11]}$. The PSO algorithm has simple coding, fewer parameters, and fast search speed. Combining PSO with BP neural network model, PSO algorithm is used to quickly find the initial weights and thresholds of BP neural network model, and the stability 
and operation efficiency of neural network model are improved. The specific process is shown in the figure below.

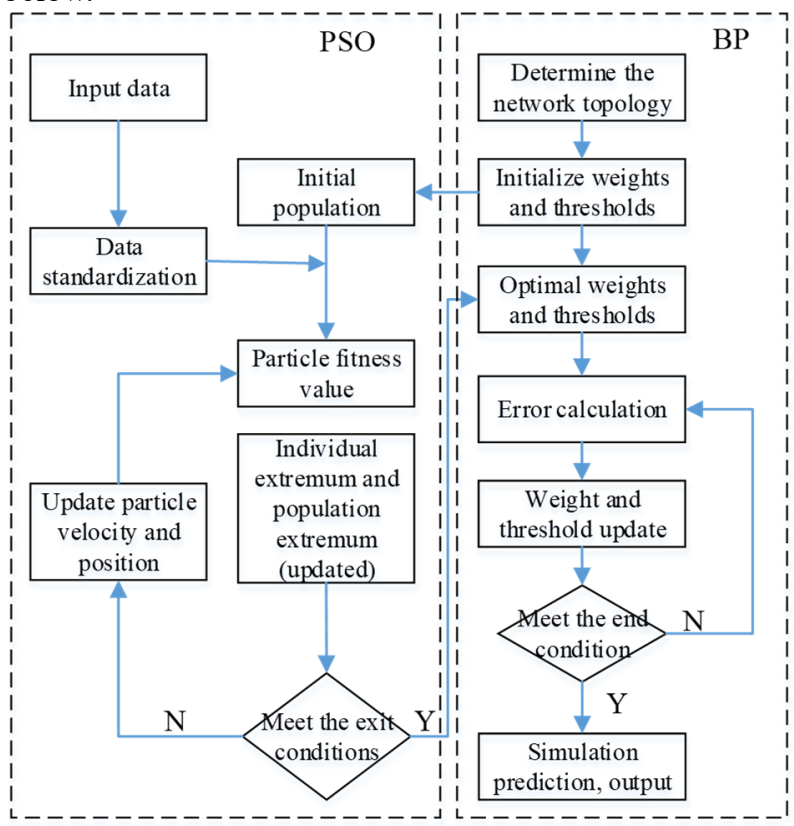

Fig. 1. $\mathrm{PSO}-\mathrm{BP}$ algorithm flow

\section{Framework of early warning mechanism for water resources carrying capacity}

\subsection{General idea}

Based on the county water management platform, the township (street) is the basic control unit, and the responsibilities of various departments are integrated, and the basic framework of the early warning mechanism of water resources carrying capacity has been constructed, including three modules: evaluation and update of carrying capacity, release of early warning information, and implementation of differentiated control measures.

\subsection{The overall framework of the early warning mechanism}

According to the responsibilities of governments and departments at all levels, this study proposes the specific water resources carrying capacity early warning mechanism process as follows:

(1) The water administrative department is responsible for proposing the index system, grading standards and calculation methods of water resources carrying capacity, incorporating them into the county water management platform, and coupling relevant monitoring data, to carry out automatic evaluation of water resources carrying capacity. At the same time, the water administrative department is responsible for formulating the update frequency of the carrying capacity index system and grading standards.

(2) Based on the evaluation, the county water administrative department will issue early warning information to the public, county-level government departments, and township (street) government and people's governments in various ways.

(3) After receiving the warning notice, the public should take the initiative to save water; The township (sub-district) people's government should vigorously carry out water conservation publicity, promote water conservation in various industries in the region, and reduce the load of water resources in the region by adjusting the industrial structure and strict enterprise entry standards; Relevant departments of the county-level government implement management and control measures in accordance with their own responsibilities by increasing the carrying capacity within the domain and reducing the carrying load.

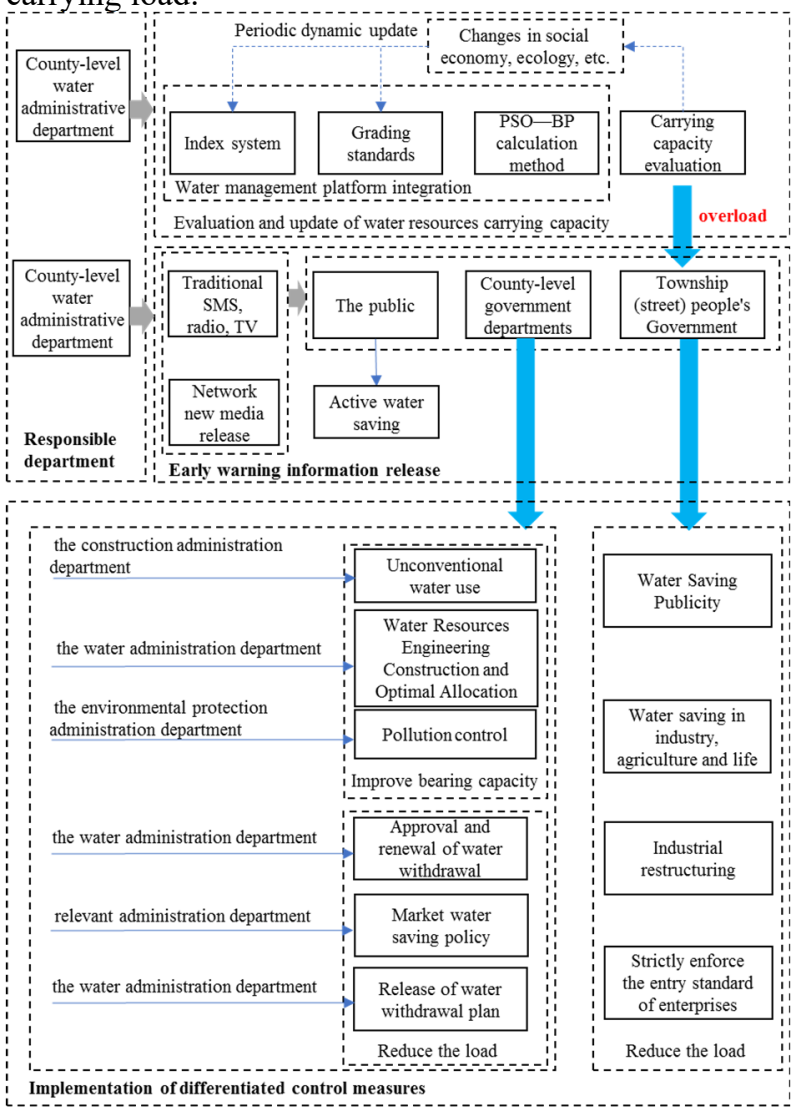

Fig. 2. Framework of early warning mechanism for water resources carrying capacity

\section{Conclusion}

Aiming at the actual needs of county water resources management, this article proposes that the indicator system should be representative, concise, and regional in the construction process of the evaluation of county water resources carrying capacity. In addition, the grading standards of water resources carrying capacity evaluation indicators need to be orderly, dynamic, scientific, and characteristic in the process of determining. Furthermore, a set of carrying capacity index system including four criterion levels of water resources, society, economy and ecology is proposed. Based on the above research, combined with the specific responsibilities of county governments at all levels and relevant departments, a general-purpose water resources carrying capacity early 
warning mechanism framework has been constructed that includes three major processes: evaluation and update of water resources carrying capacity, early warning information release, and implementation of differentiated control measures. Also, this framework clarifies the responsible body of each process.

\section{Acknowledgments}

This study was supported by the National Key Research and Development Program of China (2019YFC0408800) and Science and Technology Plan Project of Zhejiang Water Resources Department (RC2036).

\section{References}

1. Shi F, Qu Y. (1992) Water resources carrying capacity and its rational utilization in Urumqi River Basin. Beijing Science Press, Beijing.

2. Zuo Q. (2017) Review of research methods of water resources carrying capacity. Advances in science and technology of water resources, 37:5-10+58.

3. Yao Z, Wang J, Jiang D, Chen C. (2002) Advances in study on regional water resources carrying capacity and research on its theory. Advances in water science, 13:111-115.

4. Hunter C. (1998) Perceptions of the sustainable city and implications for fresh water resources management. Int. J. of Environment and Pollution, 10:84-103.

5. Xiu H, Zhu W, Wei J, Lv A. (2020) Key technologies and policies to adjust water resource-carrying capacity. J. of Beijing Normal University (Natural Science), 56:467-472.

6. Yu P, Shang M, Yao M, Liu P. (2021) Water resources carrying capacity evaluation based on water footprint and principal component analysis in Xinjiang. J. of China Hydrology, 41:49-54.

7. Jiang Y. (2019) Research on carrying capacity of water resources based on the artificial neural network - a case study in Zhaozhou county. Heilongjiang University, Harbin.

8. Fan C. (2020) The evaluation of water resources carrying capacity in Hangzhou river estuary area. Zhejiang University of Technology, Hangzhou.

9. Fan Y, Chen L, Tang W, Xu Q, Lu B. (2021) Interval prediction of river flow based on hybrid neural network and LUBE method. Water resources and power, 39:35-39.

10. Yang L, Li B, Fu Q. (2016) Scenario analysis of water resources carrying capacity in Xinjiang based on BP neural network model. J. of Beijing Normal University (Natural Science), 52:216-222.

11. Li X, Zuo Z, Li S. (2021) Research on water resources carrying capacity of shale gas development area based on GA-BP neural network. J. of Environmental Engineering Technology, 11:194-201. 